\title{
Identification with Proteomics of Novel Proteins Associated with the Peribacteroid Membrane of Soybean Root Nodules
}

\author{
S. Panter, R. Thomson, G. de Bruxelles, D. Laver, B. Trevaskis, and M. Udvardi \\ Department of Biochemistry and Molecular Biology, The Australian National University, Canberra ACT 0200, \\ Australia \\ Accepted 22 November 1999.
}

\begin{abstract}
Soybean peribacteroid membrane (PBM) proteins were isolated from nitrogen-fixing root nodules and subjected to N-terminal sequencing. Sequence data from 17 putative PBM proteins were obtained. Six of these proteins are homologous to proteins of known function. These include three chaperones (HSP60, BiP [HSP70], and PDI) and two proteases (a serine and a thiol protease), all of which are involved in some aspect of protein processing in plants. The PBM homologs of these proteins may play roles in protein translocation, folding, maturation, or degradation in symbiosomes. Two proteins are homologous to known, nodule-specific proteins from soybean, nodulin 53b and nodulin 26B. Although the function of these nodulins is unknown, nodulin $53 \mathrm{~b}$ has independently been shown to be associated with the PBM. All of the eight proteins with identifiable homologs are likely to be peripheral rather than integral membrane proteins. Possible reasons for this apparent bias are discussed. The identification of homologs of HSP70 and HSP60 associated with the PBM is the first evidence that the molecular machinery for co- or post-translational import of cytoplasmic proteins is present in symbiosomes. This has important implications for the biogenesis of this unique, nitrogen-fixing organelle.
\end{abstract}

Intracellular symbioses are widespread in nature. A common feature of these symbioses is the presence of a hostderived membrane surrounding the resident microbe(s) (Day and Udvardi 1992). This membrane and the enclosed microsymbiont(s) constitute an organelle termed the symbiosome (Roth et al. 1989). The host-derived symbiosome membrane represents both a structural and functional interface between the two symbionts and is, therefore, strategically positioned to control the molecular interactions that take place between them. Perhaps the most studied of all symbiosome membranes, and the subject of this paper, is the peribacteroid membrane (PBM) from nitrogen-fixing root nodules of legumes.

Under conditions of nitrogen deprivation, legumes can establish symbioses with nitrogen-fixing bacteria of the family

Corresponding author: Michael Udvardi; Fax: (49) 331567 8250; E-mail: udvardi@mpimp-golm.mpg.de

Current address of B. Trevaskis and M. Udvardi: Max Planck Institute of Molecular Plant Physiology, Am Mühlenberg 1, 14476 Golm, Germany.
Rhizobiaceae (called rhizobia). The legume-rhizobia symbiosis is of great ecological and agricultural importance because it allows legumes to grow in the absence of mineral or organic nitrogen in the soil. The interaction between legumes and rhizobia involves a complex molecular dialogue that culminates in the development of a novel plant organ called the root nodule (Fisher and Long 1992). Like microsymbionts in other intracellular symbioses, rhizobia take up residence in the cytoplasm of the host cell, where they are surrounded by the PBM. The PBM is formed initially via endocytosis of the plant plasma membrane (PM) or, more precisely, the infection thread membrane that is contiguous with the PM (reviewed in Whitehead and Day 1997). Subsequent, massive synthesis of the PBM relies on the endomembrane system that delivers both lipid and protein to the membrane. Some PBM proteins may also be inserted post-translationally (Simonsen and Rosendahl 1999) from the cytoplasm.

The symbiosis between legumes and rhizobia is a mutualistic one: the plant provides the nitrogen-fixing rhizobia (bacteroids) with a rich supply of reduced carbon and other nutrients in exchange for the reduced nitrogen that enables the plant to colonize nitrogen-depleted environments. Much of the metabolism of root nodules is focused on sustaining these important exchanges (reviewed by Udvardi and Day 1997). The PBM is believed to play a central role in facilitating and regulating these exchanges.

Biochemical and biophysical studies of the PBM have revealed the presence of a number of transporters that are likely to be key players in nutrient exchange between the host and its microsymbionts. One of these is a P-type $\mathrm{H}^{+}$-ATPase that generates a proton-motive-force (PMF) across the PBM by pumping protons from the infected cell cytoplasm to the peribacteroid space (PBS), the compartment between the PBM and bacteroid membranes (Blumwald et al. 1985; Domigan et al. 1988; Udvardi and Day 1989). This PMF is likely to be the driving force for many secondary transport processes, including dicarboxylate transport to and ammonium transport from the bacteroids. Dicarboxylates such as malate and succinate are believed to be the major source of reduced carbon for bacteroid metabolism and are transported across the PBM by a specific carrier (Udvardi et al. 1988; Herrada et al. 1989; Rosendahl et al. 1992). Ammonium, on the other hand, probably leaves the symbiosomes via a recently described channel (Tyerman et al. 1995). Other studies have 
provided evidence for the presence of transporters for inorganic anions, iron, calcium, and auxin (Udvardi and Day 1989; Udvardi et al. 1991; Moreau et al. 1995; LeVier et al. 1996; Andreev et al. 1998; Rosendahl and Jochimsen 1995). In addition, a number of enzyme activities have been detected on the PBM, including a pyrophosphatase, a calciumdependent protein kinase, and an iron chelate reductase (Bassarab et al. 1986; Bassarab and Werner 1987; Weaver et al. 1991; Weaver and Roberts 1992; Miao et al. 1992; LeVier et al. 1996). This list will grow as work continues on the biochemistry and electrophysiology of the PBM. However, in most cases, the genes encoding these proteins remain to be identified.

Molecular genetic studies with differential screening methods have identified cDNAs encoding several nodule-specific proteins (Fortin et al. 1987; Kouchi and Hata 1993), some of which are PBM proteins. In soybean, these include nodulins 23, 24, and 26 (Katinakis and Verma 1985; Jacobs et al. 1987; Fortin et al. 1987). These three classes of nodulins are structurally distinct. Nodulin 26 is a member of the major intrinsic protein (MIP) family of integral membrane proteins that are thought to function as water or ion channels in vivo (Sandal and Marcker 1988; Weig et al. 1997). Nodulin 26 is expressed only in infected cells within nodules. Because phosphorylation of nodulin 26 is accompanied by increases in malate uptake in symbiosomes, it is a candidate for the PBM dicarboxylate transporter (Ouyang et al. 1991), although it exhibits rather nonspecific transport activity in planar bilayers (Weaver et al. 1994). The functions of nodulins 24 and 23 are unknown.

Despite advances in our knowledge of the function of some PBM proteins and the primary structure (sequence) of others, a lack of connection between the two remains. In an attempt to bridge this gap, we are taking a number of complementary approaches to isolate genes encoding novel PBM proteins for functional studies. One of our approaches is based on proteomics, the systematic analysis of the protein complement of an organism, organ, tissue, cell, or cell fraction. Proteomics generally utilizes a combination of two-dimensional polyacrylamide gel electrophoresis (2D-PAGE), N-terminal microsequencing or protein fragmentation and mass determination, and bioinformatics (Williams et al. 1996). In this paper, we present the results of the first large-scale, systematic attempt to characterize the PBM proteome. The results are particularly relevant to the subject of targeting and processing of symbiosome proteins, about which little is currently known.

\section{RESULTS}

Before commencing PBM protein sequencing, we demonstrated that our PBM preparations were essentially free of contamination by other membranes. Previous work utilizing electron microscopy found no evidence for contamination by other organelles of soybean symbiosomes isolated in the manner employed in the present study (Price et al. 1987). The PBM is purified from isolated symbiosomes by mechanical breakage (vortexing) of symbiosomes followed by differential centrifugation to remove bacteroids. To ensure that bacteroids were not ruptured during this procedure, and that PBM preparations were not contaminated with bacteroid membranes, we used cytochrome $\mathrm{C}$ reductase activity as a marker for the bacteroid inner membrane. Succinate-cytochrome $\mathrm{C}$ reductase activity was not detected in any of our PBM preparations, despite consistently high activities of this enzyme in membranes from isolated bacteroids and nodule mitochondria (1.04 \pm 0.26 and $2.29 \pm 0.26 \mu \mathrm{mol}$ of cytochrome $\mathrm{C}$ reduced per min per $\mathrm{mg}$ of protein, respectively). Given the sensitivity of this assay (Day and Wiskich 1974), the results indicated that contamination of our PBM preparations by bacteroid and mitochondrial inner membranes was less than $1 \%$ on a protein basis. NADHferricyanide reductase activity $(0.56 \pm 0.04 \mu \mathrm{mol}$ per min per $\mathrm{mg}$ of protein) confirmed that our PBM preparations were biologically active. Similar results have been reported before (LeVier et al. 1996). In addition, it has been shown that PBM prepared in the manner employed by us is free of PM contamination (LeVier et al. 1996). Thus, the PBM preparations used in this study were essentially free of contamination by bacteroid and mitochondrial inner membranes, as well as PM.

Proteins from purified PBM were routinely separated by isoelectric focusing (IEF) followed by sodium dodecyl sulfate (SDS)-PAGE. Comparisons of Coomassie-stained gels obtained from different batches of plants indicated a high degree of reproducibility in the protein maps. Approximately 100 proteins were detected when $800 \mu \mathrm{g}$ of PBM protein was separated and stained with Coomassie R-250 (Fig. 1). In contrast, silver staining of a similar gel containing $200 \mu \mathrm{g}$ of protein from the same sample revealed about 200 proteins (Fig. 2 ). This difference was not unexpected because silver stain is approximately an order of magnitude more sensitive than Coomassie. A comparison of Coomassie- and silver-stained gels also revealed differences in the relative intensity of some stained spots, which presumably reflected differences in specific amino acid binding affinities of the two stains.

Coomassie-stained proteins separated by 2D-PAGE (IEF and SDS-PAGE) were numbered (Fig. 3) and excised directly from gels or from polyvinyl difluoride (PVDF) membranes following transfer from gels. Thirty-one of the most intensely stained spots were then subjected to $\mathrm{N}$-terminal sequencing reactions. Seventeen of these yielded sequence information, with an average read length of 15 amino acids. N-terminal sequences were compared with protein sequences present in various public data bases, using Fasta3 (Pearson and Lipman 1988). Eight of the N-terminal sequences were similar or identical to sequences of known proteins from plants and other organisms (Table 1). The search results were supported in most cases by matching molecular mass and isoelectric point data.

The N-terminal sequences of six putative PBM proteins were homologous to those of known proteins involved in translocation, processing, or degradation of other proteins. The sequences of two of these proteins, numbered $2 \mathrm{a}$ and $2 \mathrm{~b}$, were identical to each other and to the sequence of HSP60 from maize mitochondria (accession number S20875). Sequences of HSP60 family members from many other plants, including potato, pumpkin, and Arabidopsis, are also similar to those of proteins $2 \mathrm{a}$ and $2 \mathrm{~b}$. Protein 3 matched proteins from a different family of heat-shock proteins, namely endoplasmic reticulum (ER) lumenal binding proteins (BiP) from the HSP70 family. The sequence of this protein was identical to sequences from soybean, potato, tomato, and tobacco (accession numbers AAA81956, AAA99920, CAA78035, Q03685), and similar to sequences from many other plant species. HSP60 family members and $\mathrm{BiP}$ function as molecular chaperones 
and are involved in the folding, translocation, and oligomerization of proteins. For example, the mitochondrial isoform of HSP60 has been implicated in the folding of a subset of proteins imported to mitochondria from the cytosol and $\mathrm{BiP}$ is thought to be involved in the translocation and folding of proteins in the ER as well as the targeting of damaged proteins for degradation (Haas 1994; Martin 1997).

The N-terminal sequence of protein 22 was similar to that of protein disulfide isomerases (PDIs) from tobacco, al- falfa, and Arabidopsis, with between 67 and $80 \%$ identity over 15 amino acids (accession numbers Y11209, P38661, AAC62863). PDIs are members of the thioredoxin family of proteins and are involved in the isomerization of disulfide bonds during post-translational protein processing as well as being molecular chaperones for certain proteins (reviewed in Ferrari and Soling 1999).

The sequence of protein 15 was similar (73\% identity over 15 amino acids) to that of cysteine/thiol proteases from soy-

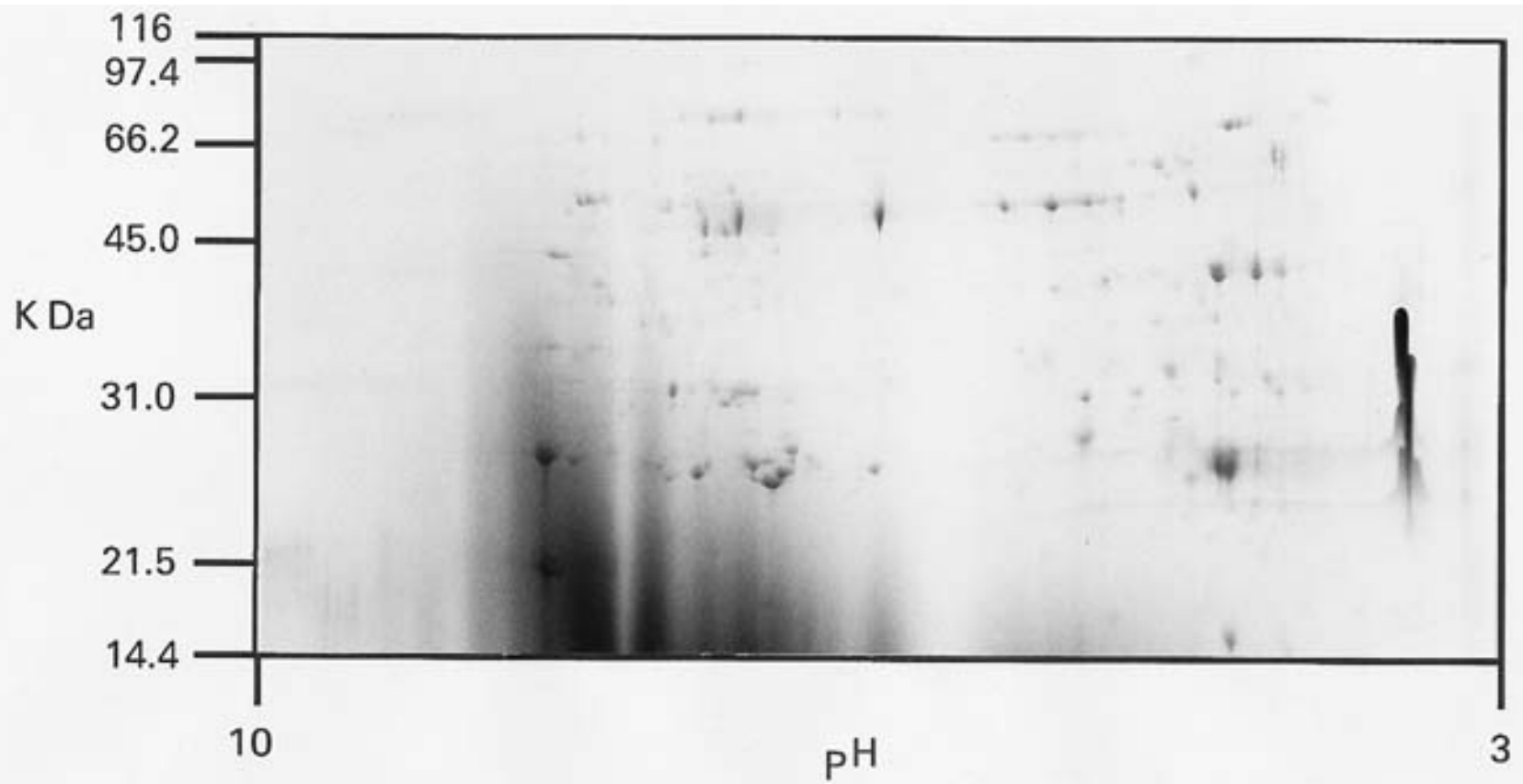

Fig. 1. A typical map of the soybean peribacteroid membrane (PBM) proteome obtained by separating $800 \mu \mathrm{g}$ of protein by isoelectric focusing (IEF) followed by sodium dodecyl sulfate-polyacrylamide gel electrophoresis (SDS-PAGE). Proteins were stained with Coomassie R-250.

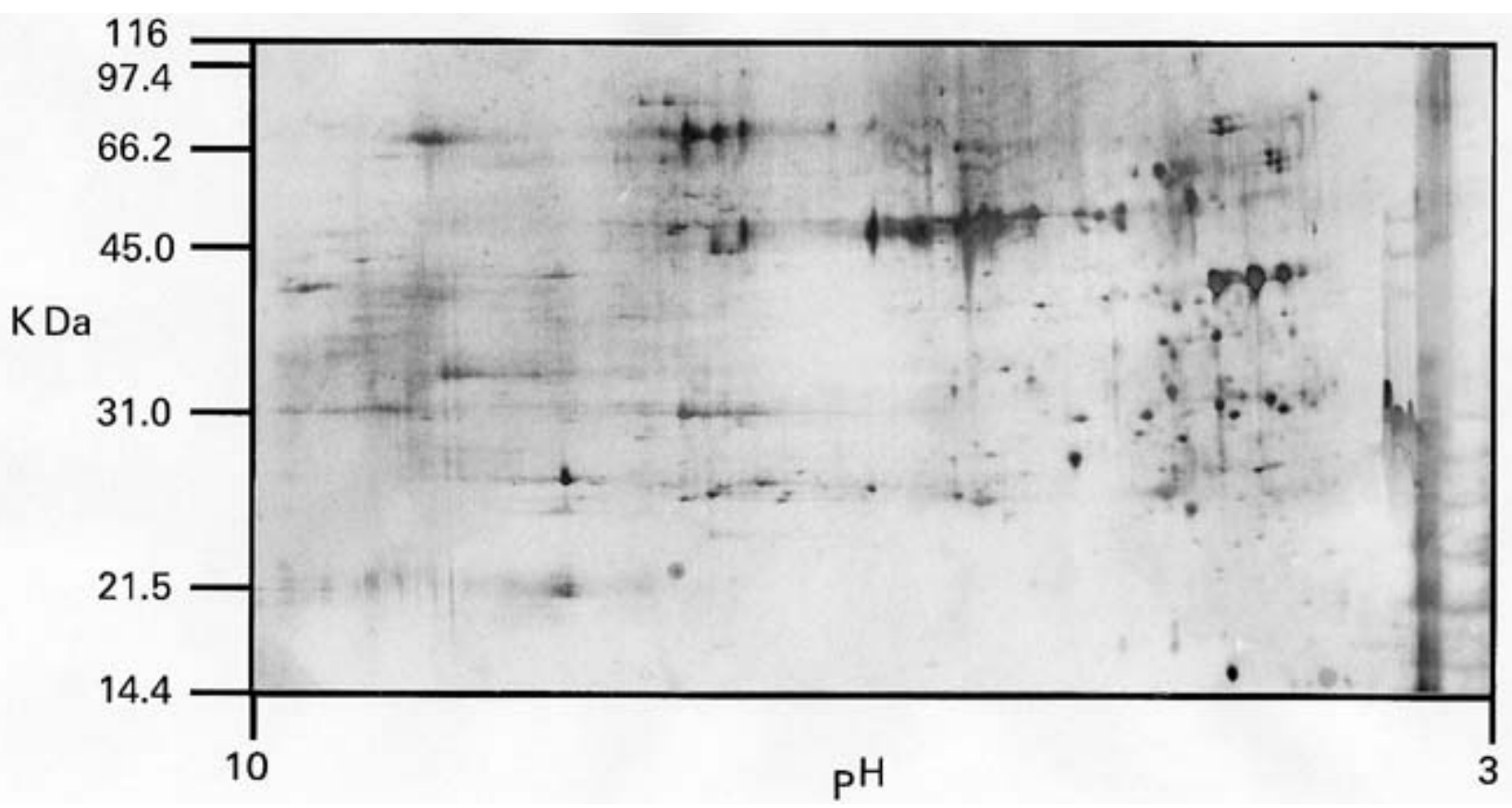

Fig. 2. Map of the soybean peribacteroid membrane (PBM) proteome obtained by separating $200 \mu \mathrm{g}$ of protein by isoelectric focusing (IEF) followed by sodium dodecyl sulfate-polyacrylamide gel electrophoresis (SDS-PAGE). Proteins were stained with silver. 
bean, Arabidopsis, chickpea, broad bean, common bean, and pea (accession numbers AAB16996, AAB16997, BAA02373, AJ009878, Z99953, U59465, P25805). Protein 18 shared 75\% sequence identity (over 12 amino acids) with subtilisin-like serine proteases from Arabidopsis and tomato (accession numbers AAD25747, CAA71234).

Two of the N-terminal sequences matched precisely those of two nodule-specific proteins from soybean with unknown functions. The sequence of protein 74 was identical to an internal stretch of 11 amino acids from nodulin $53 \mathrm{~b}$ (GmNOD53b) of the soybean PBM (Winzer et al. 1999).
Protein 102 had an N-terminal sequence identical to part of nodulin $26 \mathrm{~B}$, which belongs to a family of small nodulins from soybean. One member of this family, nodulin 23, has been localized to the PBM in the past (Jacobs et al. 1987).

Sequence alignments (not shown) revealed that the $\mathrm{N}$ terminus of the putative PBM proteins did not coincide with the $\mathrm{N}$ terminus of their closest homologs. In fact, sequence matches began from 24 to 210 amino acids from the predicted $\mathrm{N}$-terminal end of homologous proteins (Table 1). This suggests that each of the PBM proteins with known homologs was processed en route to or at the PBM.

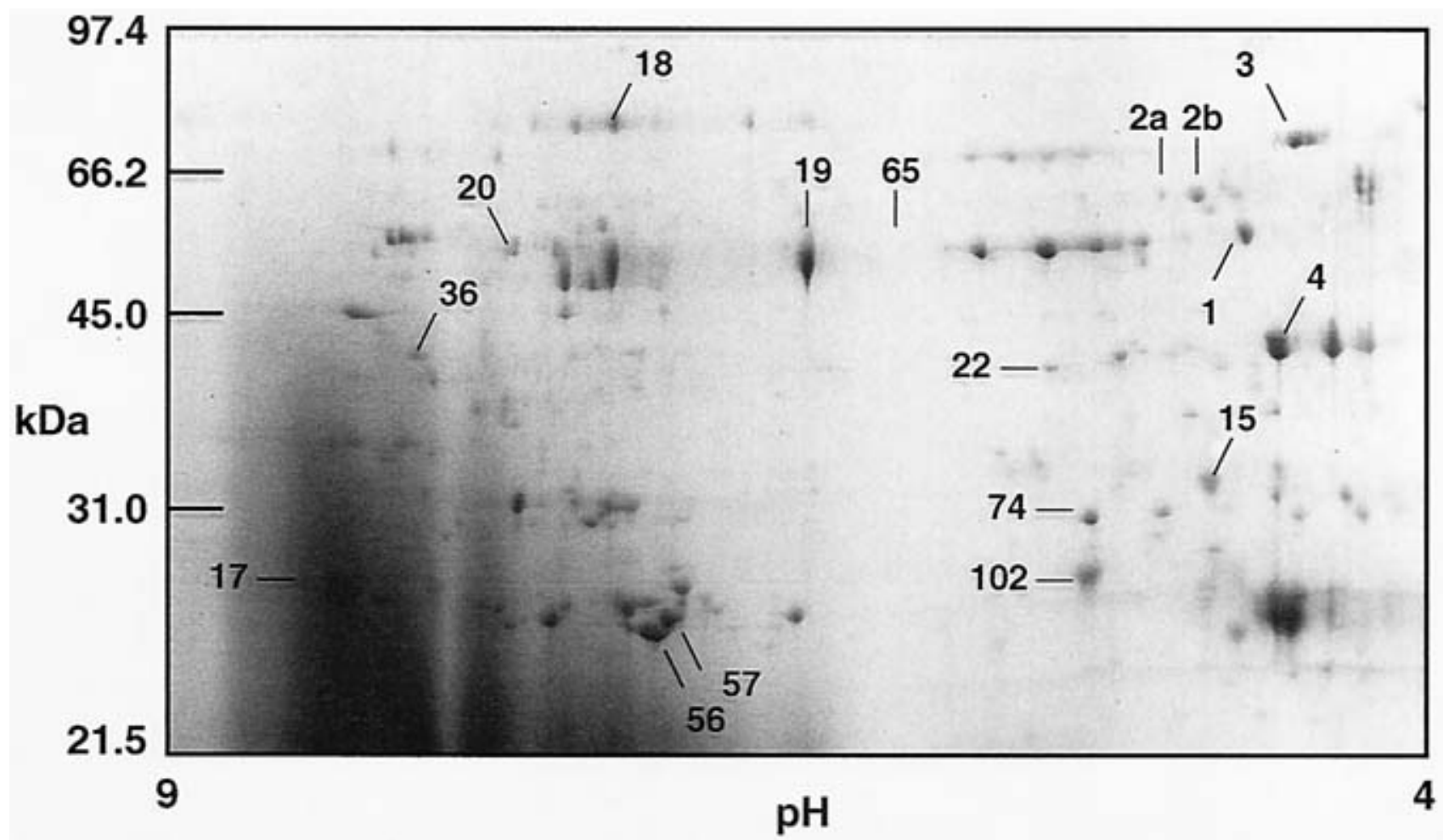

Fig. 3. Map of the soybean peribacteroid membrane (PBM) proteome indicating Coomassie-stained proteins that were sequenced successfully.

Table 1. N-terminal amino acid sequence of putative peribacteroid membrane (PBM) proteins and similarity to known proteins

\begin{tabular}{|c|c|c|c|c|c|c|}
\hline Protein & $\begin{array}{l}\text { Molecular } \\
\text { mass (kDa) }\end{array}$ & Sequence & Homologs $^{\text {a }}$ & $\begin{array}{c}\mathbf{E} \\
\text { value }^{b}\end{array}$ & Identity (\%) & $\begin{array}{l}\text { Match } \\
\text { start }^{\mathrm{c}}\end{array}$ \\
\hline 1 & 55 & $\mathrm{ATA}_{5} \mathrm{~T}(\mathrm{~A} / \mathrm{P}) \mathrm{PPS}(\mathrm{A} / \mathrm{P}) \mathrm{P}_{3} \mathrm{GKKE}$ & None & & & \\
\hline $2 \mathrm{a} / \mathrm{b}$ & 60 & AAKDIKFGVEARALM & Zea mays mitochondrial HSP60 (S20875) & $1 \mathrm{e}-05$ & $100 \%(15 / 15)$ & 35 \\
\hline 3 & 70 & KEEATKLGTVIGIDL & Glycine max BiP (AAA81956) & 0.0004 & $100 \%(15 / 15)$ & 31 \\
\hline 4 & 41 & ENKLPESLLIPYSG & None & & & \\
\hline 15 & 33 & LPSDAQKAPILPTXD & Glycine max thiol protease (AAB16997) & 0.02 & $73 \%(11 / 15)$ & 73 \\
\hline 17 & 28 & $\begin{array}{l}\text { ADLPVYKKAP3VEA } \\
\text { FNPWMVVLLVLG }\end{array}$ & None & & & \\
\hline 18 & 80 & TTSTPQFLGLQK & Arabidopsis thaliana sbtilisin protease (AAD25747) & 0.3 & $75 \%(9 / 12)$ & 100 \\
\hline 19 & 50 & EGMDFSELRKAVEEV LDSHS & None & & & \\
\hline 20 & 53 & SLVTGKPSSVPFSVP & None & & & \\
\hline 22 & 40 & $\mathrm{QDV}_{3} \mathrm{LSELNFEKEV}$ & $\begin{array}{l}\text { Nicotiana tabacum protein disulfide-isomerase } \\
\text { (Y11209) }\end{array}$ & 0.003 & $73 \%(11 / 15)$ & 24 \\
\hline 36 & 41 & NATNIPKKTS & None & & & \\
\hline $56 / 57$ & 26 & ADLAARPYTKAP & None & & & \\
\hline 65 & 50 & EGMEFSELRDAVE & None & & & \\
\hline 74 & 31 & AETKIISTQRQ & Glycine max Nodulin 53b (AF065435) & 0.0002 & $100 \%(11 / 11)$ & 207 \\
\hline 102 & 29 & EDADNIGEAIIPP & Glycine max Nodulin 26B (P08863) & 0.0009 & $92 \%(12 / 13)$ & 15 \\
\hline
\end{tabular}

${ }^{a}$ Obtained by Fasta3 searches of public protein data bases.

b The probability that the listed match occurred by chance alone.

${ }^{c}$ Indicates the amino acid position in the homologous protein where the match with the putative PBM protein begins. 
Only "homologs" with E values less than 0.5 are reported in Table 1. These correspond to matches that had less than $50 \%$ probability of occurring by chance alone. In all but two cases, the probability was much less than $1 \%$ (E less than 0.01) that the match was a chance event. The exceptions to this were proteins 15 and 18. Their tentative identification as proteases is supported by the similarity in the molecular mass of the sequenced proteins and that predicted from the DNA sequence of the known proteases.

Nine of the 17 proteins sequenced in this project did not show significant similarity to known proteins. These "orphan" proteins may represent novel plant proteins, although confirmation of this will require complete sequence for each protein.

\section{DISCUSSION}

\section{Assessment of the purity of the PBM fraction.}

In any biochemical study of isolated organelles or other cell fractions, the purity or homogeneity of the experimental material is important. Obviously, the same is true for proteomics. In this study, we interpreted the absence of succinatecytochrome $\mathrm{C}$ reductase activity as evidence that the PBM preparations lacked bacteroid and mitochondrial inner membranes. The latter conclusion was consistent with previous electron microscopy that found no evidence for organelle contamination of soybean symbiosomes prepared in the same way (Price et al. 1987). Although breakage of symbiosomes by vortexing may lead to some contamination of PBM preparations with bacteroid outer membrane (Streeter and Morre 1990), such contamination apparently was not a significant problem in our study since none of the sequenced proteins matched proteins of bacterial origin. Soluble proteins that come into contact with the PBM during nodule disruption and symbiosome isolation represent another potential source of contamination. However, washing of our final PBM preparations with high salt ( $2 \mathrm{M} \mathrm{NaBr}$ ) to remove loosely bound, peripheral membrane proteins did not alter the number and intensity of Coomassie-stained proteins visualized after SDSPAGE. This wash was not included routinely in our PBM purification protocol because it resulted in a substantial decrease in PBM recovery.

\section{Peripheral proteins appear to dominate the PBM landscape.}

Surprisingly, all of the putative PBM proteins that matched known proteins are likely to be peripheral rather than integral membrane proteins, based on hydropathy analysis (not shown). The first proteome analysis of the Arabidopsis PM yielded similar results (Santoni et al. 1998). Taken together, the results obtained from the PBM of soybean and PM of Arabidopsis indicate that peripheral proteins may play important, previously unsuspected roles in membrane biology. However, an important question remains: Are the 2D protein maps obtained in these studies true representations of the diversity and abundance of proteins in the PBM and PM? It has been suggested that under-representation of integral membrane proteins in the Arabidopsis PM proteome study may have resulted from inefficient solubilization and recovery of the hydrophobic proteins during sample preparation (Santoni et al. 1998). Although this is one possible explanation for the apparent paucity of hydrophobic proteins from the PBM, at least two other factors may have contributed to the lack of integral membrane proteins. First, aggregation of hydrophobic proteins during IEF, either at their isoelectric point or earlier, may have occurred. Hydrophobic protein aggregates may be quite insoluble and, therefore, recalcitrant to 2D-PAGE. In our experiments, we loaded the protein sample at the acidic end of the IEF gel. Western blot (immunoblot) analysis with antibodies against the most abundant of the integral PBM proteins, nodulin 26 , indicated that it was located at the acidic end of the IEF gradient despite its predicted neutral isoelectric point. Thus, nodulin 26 appeared to have precipitated in the sample cup during IEF (note that nodulin 26 is not related to nodulin $26 \mathrm{~B}$, which was sequenced in this study). Although loading the IEF gel by applying protein sample over the full length of the gel (Santoni et al. 1998) may reduce this problem, it is unlikely to eliminate the problem altogether for the most abundant of the hydrophobic proteins.

Another factor that may have contributed to the apparent under-representation of integral membrane proteins in this and previous proteome projects could be the choice of stain used to visualize the proteins. Coomassie R-250 stains arginine and lysine preferentially (Congdon et al. 1993). If these basic amino acids are under-represented in hydrophobic, integral membrane proteins then such proteins will be poorly stained by Coomassie and consequently overlooked by any strategy that focuses on the most heavily stained proteins. Consistent with this idea, comparison of Coomassie- and silver-stained gels (Figs. 1 and 2) indicated that some proteins are poorly stained by Coomassie relative to silver, and vice versa.

\section{Possible new functions at the PBM.}

Most of the proteins identified during this study have not been associated with the PBM in the past. Four of the proteins share sequence similarity with chaperones, proteins that mediate the correct folding and assembly of other polypeptides, without becoming part of the final, functional structure. Chaperones are present in most if not all cellular compartments and are required wherever proteins must be folded de novo, stabilized under stress conditions, or modulated to regulate activity (Hendrick and Hartl 1993). Some chaperones, for example the HSP70 family, are also involved in the membrane translocation of proteins and, therefore, organelle biogenesis. HSP70 homologs have been found in plant mitochondria, plastids, ER, and peroxisomes (reviewed in: Glaser et al. 1998; Soll and Tien 1998; Galili et al. 1998; Olsen 1998) where they may act as a molecular ratchet to facilitate protein import (Matlack et al. 1999). The putative PBM protein 3 matches BiP (HSP70) sequences in different plant species. Proteins 2a and $2 b$, on the other hand, match mitochondrial chaperones of the HSP60 family. HSP70 and HSP60 proteins often act sequentially to achieve protein import and folding in organelles (Hendrick and Hartl 1993). The presence of homologues of these proteins on the PBM suggests that symbiosomes may import some proteins directly from the cytoplasm in vivo. This hypothesis is consistent with the recent work of Simonsen and Rosendahl (1999), which showed that isolated pea symbiosomes can import in vitro-translated nodule proteins. Thus, symbiosome biogenesis may be more complex than previously thought. It is generally believed that PBM and PBS constituents are derived from the ER/Golgi system (Whitehead and Day 1997). An alternative, additional pathway of 
protein import from the cytoplasm may allow the cell greater flexibility in tailoring the protein complement of symbiosomes. It will be interesting to determine which, if any, of the symbiosome proteins are targeted in this way.

The putative PBM protein 22 is homologous to a different molecular chaperone, PDI. PDI catalyzes disulfide bond formation and rearrangements and is necessary for the correct folding of many proteins (Gilbert 1997). It is normally resident in the ER lumen but apparently not confined there: It was recently found in association with the PM of Arabidopsis (Santoni et al. 1998). In animals, PDIs on the PM are involved in receptor processing (Couet et al. 1996; Terada et al. 1995). Given the important roles that molecular chaperones like PDI, HSP70, and HSP60 may play in symbiosome biogenesis and function, it will be interesting to determine whether these proteins represent nodule-specific or noduleenhanced isoforms.

PBM homologs of two types of proteases, a thiol protease (protein 15) and a serine protease (protein 18), were also found. Thiol and serine proteases have been found in the vacuoles of plant cells, a compartment that is thought to be replaced by symbiosomes in infected cells of legume root nodules (reviewed in Vierstra 1996). The vacuole contains a number of proteases that are implicated in the hydrolysis and recycling of damaged proteins and with defense responses in plants. A pea cysteine protease is induced by root nodule senescence and may be required for remobilizing amino acids from degraded symbiotic proteins (Kardailsky and Brewin 1996). On the other hand, a nodule-specific serine protease from Alnus glutinosa is thought to be involved in the processing of symbiotic proteins during early nodulation (Ribiero et al. 1995). Some thiol proteases have been found to hydrolyze proteins specifically tagged by ubiquitin, mediating protein turnover (Vierstra 1996). It will be interesting to determine at what stage(s) of nodule development the putative PBM thiol and serine proteases are expressed, and their substrates. This information may reveal whether they are involved in the processing or in the turnover of symbiotic proteins.

Two of the amino acid sequences presented in Table 1 match precisely those of two nodule-specific proteins of soybean: nodulin 53b (GmNOD53b: Winzer et al. 1999) and nodulin 26B (Jacobs et al. 1987). Both are of unknown function but nodulin $53 \mathrm{~b}$ has been found to be associated with the PBM before (Winzer et al. 1999). The intracellular location of nodulin 26B has remained unknown until now. Nodulin 26B is a member of a family of small nodulins characterized by three homologous domains and three to four conserved cysteine residues that are thought to form a metal-binding motif (Jacobs al. 1987; Sandal et al. 1987). Neither nodulin 53b nor nodulin $26 \mathrm{~B}$ is predicted to have transmembrane domains, although myristoylation may be the means of anchoring GmNOD53b to the membrane (Winzer et al. 1999). A sequence comparison indicated that protein 74 was derived by proteolysis of GmNOD53 (see Table 1): Hence the much lower mass of the former $(31 \mathrm{kDa})$ compared with the latter $(53 \mathrm{kDa})$. The fact that protein 74 was present as a discrete and abundant spot on stained 2D gels indicates that it is likely to be a processed form of GmNOD53b rather than a random degradation product. It will be interesting to determine the biological role(s) of the two forms of the protein.
Approximately half (9/17) of the sequenced proteins had no significant match to known proteins. The fraction of Arabidopsis PM proteins that did not match any data base entry was substantially lower at $24 \%$ (Santoni et al. 1998). The difference presumably reflects the fact that much more of the Arabidopsis genome, including expressed sequence tags (ESTs), has been sequenced, compared with the soybean genome. Indeed, many of the putative Arabidopsis PM sequences matched Arabidopsis ESTs, although many of these have not yet been assigned a function. Divergence of PBM protein sequences may also have contributed to the relatively high proportion of orphan proteins in soybean. In fact, given the unique role of the PBM in symbiotic nitrogen fixation, one might expect that PBM proteins have diverged substantially from their ancestors, and from their homologs in other plants. The full extent of this divergence will only be known when complete sequence for all PBM proteins is obtained.

Nearly half of all proteins submitted for sequencing (14/31) did not yield sequence information despite being heavily stained with Coomassie R-250, presumably because they were chemically blocked. Blockage is common for plant proteins and is caused by acetylation, glycosylation, or the addition of a pyrrolidone carboxylate group to the $\mathrm{N}$-terminal amino acid residue (Narita 1958; Press et al. 1966; Takahashi et al. 1985; Wellner et al. 1990). This problem could be overcome by digesting proteins with proteases and sequencing the resulting internal peptides (Santoni et al. 1998).

\section{N-terminal processing and targeting of PBM proteins.}

Comparisons of the N-terminal sequences of the PBM proteins with the predicted sequences of their homologs in soybean and other species showed that most of the former had probably been processed. The estimated number of amino acids removed from the $\mathrm{N}$-terminal end of the proteins ranged from 14 to 34 in the cases of nodulin 26B, PDI, BiP (HSP70), and HSP60, to 72 to 99 for the thiol and serine proteases. Processing of the homolog of nodulin 53b appears to have been more dramatic: it is likely that 206 amino acids were removed from the N-terminal end of the sequenced protein. It is possible that the sequences removed from some of the PBM proteins, especially nodulin 26B, PDI, BiP, and HSP60, represent signal sequences. For instance, the full-length soybean nodulin $26 \mathrm{~B}$ is predicted to have a cleavable $\mathrm{N}$-terminal signal with a cleavage site after amino acid 14 (Nakai and Kanehisa 1992). Cleavage at this position would produce an N-terminal sequence identical to the one determined by us. Despite the likelihood that progenitors of some of the PBM proteins have signal sequences, it is not possible to say by which route they arrive at the PBM. Removal of a signal sequence in the ER would be consistent with delivery of PBM proteins via the endomembrane system. However, many proteins that are imported from the cytoplasm into other organelles are also cleaved at the $\mathrm{N}$ terminus.

In summary, a proteomics approach utilizing 2D-PAGE and $\mathrm{N}$-terminal protein sequencing has enabled us to identify a number of novel putative PBM proteins from soybean root nodules. Eight of the proteins share sequence similarity with known proteins, five of which have known functions. The homologs with known function are all involved in various aspects of protein processing in plants, including translocation, folding, cross-linking, and degradation. The putative PBM 
homologs may, therefore, contribute to the insertion, activation, maintenance, and turnover of symbiosome proteins. Two of these proteins are of particular interest: They are homologs of HSP60 and BiP (HSP70), and may play a role in co- or post-translational insertion of proteins into symbiosomes in vivo. Thus, they may play important roles in an alternative pathway of PBM biogenesis in nodules. The N-terminal sequence of two other proteins matched precisely two soybean nodulins, one of which had been found on the PBM previously. Nine sequences did not show significant similarity to any other proteins. Currently, we are using the N-terminal sequence information presented here to isolate full-length cDNA encoding each of the putative PBM proteins, with a view to determining their functions and physiological roles. Ultimately, in situ methods that do not disrupt nodule ultrastructure, such as immunolocalization of specific proteins in fixed sections of nodules, will be required to confirm a PBM location for the proteins described here. We are also working toward this end.

\section{MATERIALS AND METHODS}

\section{Cultivation of soybean plants.}

Soybean seeds (Glycine max cv. Stevens) were inoculated with Bradyrhizobium japonicum USDA110 and grown in a glasshouse as described previously (Delves et al. 1986). Plants were watered on alternate days with water and Herridge (1982) nutrients without nitrate, which was applied at $1 / 4$ strength for the first 6 weeks after sowing and at $1 / 2$ strength thereafter.

\section{Isolation of PBM proteins.}

All steps except for phenol extraction were performed at $4{ }^{\circ} \mathrm{C}$ to minimize proteolytic activity. Ten to 20 grams of mature nodules from 8- to 9-week-old soybean plants were harvested and symbiosomes were isolated with three-step Percoll gradients (Price et al. 1987). The symbiosome pellet was resuspended in $10 \mathrm{ml}$ of wash buffer $(350 \mathrm{mM}$ mannitol; $25 \mathrm{mM}$ MES-KOH, pH 7; $3 \mathrm{mM} \mathrm{MgSO}_{4} \cdot 7 \mathrm{H}_{2} 0$ ) containing $1 \mathrm{mM}$ D-L dithiothreitol and the protease inhibitors trans-epoxysuccinly-L-leucamido (4-guanidino) butane (E64 at $5 \mu \mathrm{M}$ ) and phenylmethylsulfonyl fluoride (PMSF at 1 $\mathrm{mM}$ ). The mixture was vortexed vigorously for $2 \mathrm{~min}$, then centrifuged at $4,000 \times g$ for 6 min with a Sorvall HB-4 rotor to pellet free bacteroids and any unbroken symbiosomes. The supernatant was removed and centrifuged at 20,000 $\times g$ for $20 \mathrm{~min}$ in a Sorvall SS34 rotor. The supernatant, which was essentially free of bacteroids, was then centrifuged at $400,000 \times g$ for $1 \mathrm{~h}$ with a Ti80 rotor in a Beckman LM70M centrifuge to pellet the PBM. After removal of the supernatant containing PBS components, the pellet was gently rinsed with wash buffer. The pellet was then homogenized in a glass homogenizer with a Teflon plunger and phenolextracted to remove phospholipids and nucleic acids (Hurkman and Tanaka 1986). Phenol-extracted protein was precipitated by adding 5 volumes of methanol containing 0.1 $\mathrm{M}$ ammonium acetate and incubating for $14 \mathrm{~h}$ at $-20^{\circ} \mathrm{C}$. The precipitate was pelleted by centrifugation for $5 \mathrm{~min}$ at $12,000 \mathrm{rpm}$ in a microcentrifuge (centrifuge 5417; Eppendorf, Hamburg, Germany). Protein pellets were washed three times with $0.1 \mathrm{M}$ ammonium acetate in methanol, then once with acetone. Samples were dried on ice under a stream of argon and stored at $-70^{\circ} \mathrm{C}$. Protein content of small aliquots was determined by a modified Lowry assay (Peterson 1977).

\section{Enzyme assays.}

Succinate-cytochrome $\mathrm{C}$ reductase activity was measured according to Day and Wiskich (1974). NADH-ferricyanide reductase activity was determined as described by LeVier et al. (1996).

\section{D-PAGE and N-terminal sequencing.}

2D-PAGE was performed with the Multiphor 2 system from Pharmacia (Uppsala, Sweden; O'Farrell 1970). Protein preparations were pooled and solubilized in $9 \mathrm{M}$ urea, $4 \% \mathrm{wt} / \mathrm{vol}$ CHAPS (3-[(3-cholamidopropyl)-dimethylammonio]-1-propane-sulfonate), $1 \% \mathrm{wt} / \mathrm{vol}$ dithiothreitol, $0.8 \% \mathrm{vol} / \mathrm{vol}$ Pharmacia ampholines ( $\mathrm{pH} \mathrm{3-10),} 70 \mathrm{mM}$ Tris and bromophenol blue (approximately $2 \mu \mathrm{g}$ of protein per $\mu \mathrm{l}$ ) by gentle shaking for an hour at ambient temperature (approximately $24^{\circ} \mathrm{C}$ ). Solubilized proteins $(200 \mu \mathrm{g})$ were loaded into a sample cup at the acidic end of a $18-\mathrm{cm}, \mathrm{pH} 3-10$, nonlinear IEF strip. Four loadings containing a total of $800 \mu \mathrm{g}$ of protein were used for preparative gels. 2D-PAGE was performed essentially according to the Pharmacia protocol, with a 12 to $14 \%$ acrylamide SDS-PAGE second dimension. Bio-Rad (Hercules, CA) broad-range molecular mass markers were loaded onto each side of the second dimension. Coomassie staining involved incubation of gels in $0.05 \% \mathrm{wt} / \mathrm{vol}$ Coomassie R-250, $40 \%$ $\mathrm{vol} / \mathrm{vol}$ methanol, $10 \% \mathrm{vol} / \mathrm{vol}$ glacial acetic acid followed by destaining in $3 \% \mathrm{vol} / \mathrm{vol}$ glycerol, $20 \% \mathrm{vol} / \mathrm{vol}$ methanol, and $7 \% \mathrm{vol} / \mathrm{vol}$ glacial acetic acid. Silver staining of separate gels was performed by the method of Merril et al. (1981). Individual stained proteins were either cut directly from Coomassiestained gels with sterile scalpel blades, or cut from Coomassie-stained PVDF membranes after electrophoretic transfer (Matsudaira 1987). Proteins were stored at $-70^{\circ} \mathrm{C}$ prior to $\mathrm{N}$ terminal amino acid sequencing with either an HT or a CLC Procise sequencer (Applied Biosystems, Foster City, CA). Sequencing was done at the Biomolecular Resource Facility of the Australian National University.

\section{Bioinformatics.}

$\mathrm{N}$-terminal amino acid sequences were compared with protein sequences in various data bases, using the online Fasta3 sequence alignment program (Pearson and Lipman 1988).

\section{ACKNOWLEDGMENTS}

We would like to thank Megan McKenzie for technical advice and editorial assistance, and Jim Whelan for reviewing the manuscript. This work was funded by the Australian Research Council.

\section{LITERATURE CITED}

Andreev, I. M., Dubrovo, O. N., Krylova, K. Y., and Izmailov, S. F. 1998. Calcium uptake by symbiosomes and the peribacteroid membrane vesicles isolated from yellow lupin root nodules. J. Plant. Physiol. 153:610-614.

Bassarab, S., Mellor, R. B., and Werner, D. 1986. Evidence for two types of Mg-ATPase in the peribacteroid membrane from Glycine max root nodules. Endocyt. Cell Res. 3:189-196.

Bassarab, S., and Werner, D. 1987. $\mathrm{Ca}^{2+}$-dependent protein kinase activ- 
ity in the peribacteroid membrane from soybean root nodules. J. Plant Physiol. 130:233-241.

Blumwald, E., Fortin, M. G., Phillips, A. R., Verma, D. P. S., and Poole, R. J. 1985. Presence of host plasma membrane-type ATPase in the membrane envelope surrounding the bacteroids in soybean root nodules. Plant Physiol. 78:665-672.

Congdon, R. W., Muth, G. W., and Splittgerber, A. G. 1993. The binding interaction of Coomassie blue with proteins. Anal. Biochem. 213:407413.

Couet, J., Bernard, S. D., Loosfelt, H., Saunier, B., Milgrom, E., and Mirashi, M. 1996. Cell surface protein disulfide-isomerase is involved in the shedding of human thyotropin receptor ectodomain. Biochemistry. 35:14800-14805.

Day, D. A., and Udvardi, M. K. 1992. Metabolite exchange across symbiotic membranes. Symbiosis 14:175-189.

Day, D. A., and Wiskich, J. T. 1974. The oxidation of malate and exogenous reduced nicotinamide adenine dinucleotide by isolated plant mitochondria. Plant Physiol. 53:104-109.

Delves, A. C., Matthews, A., Day, D. A., Carter, A. S., Carroll, B. J., and Gresshoff, P. M. 1986. Regulation of the soybean-Rhizobium nodule symbiosis by shoot and root factors. Plant Physiol. 82:588-590.

Domigan, N. M., Farnden, K. J. F., Robertson, J. G., and Monk, B. C. 1988. Characterisation of the peribacteroid membrane ATPase of lupin root nodules. Arch. Biochem. Biophys. 264:564-573.

Ferrari, D. M., and Soling, H.-D. 1999. The protein disulfide-isomerase family: Unravelling a string of folds. Biochem. J. 339:1-10.

Fisher, R. F., and Long, S. R. 1992. Rhizobium-plant signal exchange. Nature 357:655-660.

Fortin, M. G., Morrison, N. A., and Verma, D. P. S. 1987. Nodulin 26, a peribacteroid membrane nodulin, is expressed independently of the development of the peribacteroid membrane. Nucleic Acids Res. 15: 813-824.

Galili, G., Sengupta-Gopalan, C., and Ceriotti, A. 1998. The endoplasmic reticulum of plant cells and its role in protein maturation and biogenesis of oil bodies. Plant Mol. Biol. 38:1-29.

Gilbert, H. F. 1997. Protein disulfide isomerase and assisted protein folding. J. Biol. Chem. 272:29399-29402.

Glaser, E., Sjöling, S., Tanudji, M., and Whelan, J. 1998. Mitochondrial protein import in plants. Plant Mol. Biol. 38:311-338.

Haas, I. G. 1994. BiP (GRP78), an essential hsp78 resident protein in the endoplasmic reticulum. Experientia 50:1012-1020.

Hendrick, J. P., and Hartl, F.-U. 1993. Molecular chaperone functions of heat-shock proteins. Annu. Rev. Biochem. 62:349-384.

Herrada, G., Puppo, A., and Rigaud, J. 1989. Uptake of metabolites by bacteroid-containing vesicles and by free bacteroids from french bean nodules. J. Gen. Microbiol. 135:3165-3171.

Herridge, D. F. 1982. Use of the ureide technique to describe the nitrogen economy of field-grown soybeans. Plant Physiol. 70:7-11.

Hurkman, W. J., and Tanaka, C. K. 1986. Solubilisation of plant membrane proteins for analysis by two-dimensional gel electrophoresis. Plant Physiol. 81:802-806.

Jacobs, F. A., Zhang, M., Fortin, M. G., and Verma, D. P. S. 1987. Several nodulins of soybean share structural domains but differ in their subcellular locations. Nucleic Acids Res. 15:1271-1280.

Kardailsky, I. V., and Brewin, N. J. 1996. Expression of cysteine protease genes in pea nodule development and senescence. Mol. PlantMicrobe Interact. 9:689-695.

Katinakis, P., and Verma, D. P. S. 1985. Nodulin-24 gene of soybean encodes for a peptide of the peribacteroid membrane and was generated by tandem duplication of a sequence resembling an insertion element. Proc. Natl. Acad. Sci. USA 82:4157-4161.

Kouchi, H., and Hata, S. 1993. Isolation and characterisation of novel nodulin cDNAs representing genes expressed at early stages of soybean nodule development. Mol. Gen. Gen. 238:106-119.

LeVier, K., Day, D. A., and Guerrinot, M. M. 1996. Iron uptake by symbiosomes from soybean root nodules. Plant Physiol. 111:893-900.

Martin, J. 1997. Molecular chaperones and mitochondrial protein folding. J. Bioenerg. Biomembr. 29:35-43.

Matlack, K. E. S., Misselwitz, B., Plath, K., and Rapoport, T. A. 1999. $\mathrm{BiP}$ acts as a molecular ratchet during posttranslational transport of prepro- $\alpha$ factor across the ER membrane. Cell 97:553-564.

Matsudaira, P. 1987. Sequence from picomole quantities of proteins electroblotted onto PVDF membrane. J. Biol. Chem. 262:10035-10038.

Merril, C. R., Dunau, M. L., and Goldman, D. 1981. A rapid sensitive silver stain for polypeptides in polyacrylamide gels. Anal. Biochem. 110:201-207.

Miao, G. H., Hong, Z., and Verma, D. P. 1992. Topology and phosphorylation of soybean nodulin-26, an intrinsic protein of the peribacteroid membrane. J. Cell Biol. 118:481-490.

Moreau, S., Meyer, J. M., and Puppo, A. 1995. Uptake of iron by symbiosomes and bacteroids from soybean nodules. FEBS Lett. 361:225228.

Nakai, K., and Kanehisa, M. 1992. A knowledge base for predicting protein localization sites in eukaryotic cells. Genomics 14:897-911.

Narita, K. 1958. Isolation of acetyl peptide from enzymic digests of TMV protein. Biochim. Biophys. Acta. 28:184-191.

O'Farrell, P. 1970. High resolution two-dimensional electrophoresis of proteins. J. Biol. Chem. 250:4007-4021.

Olsen, L. J. 1998. The surprising complexity of peroxisome biogenesis. Plant Mol. Biol. 38:163-189.

Ouyang, L. J., Whelan, J., Weaver, C. D., Roberts, D. M., and Day, D. A. 1991. Protein phosphorylation stimulates the rate of malate transport across the peribacteroid membrane of soybean nodules. FEBS Lett. 293:188-190.

Pearson, W. R., and Lipman, D. J. 1988. Improved tools for biological sequence comparison. Proc. Natl. Acad. Sci. USA 85:2444-2448.

Peterson, G. L. 1977. A simplification of the protein assay method of Lowry which is generally more applicable. Anal. Biochem. 83:346356.

Press, E. M., Piggot, P. J., and Porter, R. R. 1966. The N- and C-terminal amino acid sequences of the heavy chain from a pathological human immunoglobulin IgG. Biochem. J. 99:356-366.

Price, G. D., Day, D. A., and Gresshoff, P. M. 1987. Rapid isolation of intact peribacteroid envelopes from soybean nodules and demonstration of selective permeability to metabolites. J. Plant Physiol. 130: 157-164.

Ribiero, A., Akkermans, A. D. L., van Kammen, A., Bisseling, T., and Pawlowski, K. 1995. A nodule-specific gene encoding a subtilisin-like protease is expressed in early stages of actinorhizal nodule development. Plant Cell 7:785-794.

Rosendahl, L., Dilworth, M. J., and Glenn, A. R. 1992. Exchange of metabolites across the peribacteroid membrane in pea root nodules. J. Plant Physiol. 139:635-638.

Rosendahl, L., and Jochimsen, B. U. 1995. Uptake of indole-3-acetic acid in symbiosomes from soybean (Glycine max L.) root nodules. Page 591 in: Nitrogen Fixation: Fundamentals and Applications. I. A. Tikhonovich, N. A. Provorov, V. I. Romonov, and W. E. Newton, eds. Kluwer Academic Publishers. Dordrecht, The Netherlands.

Roth, E., Jeon, K., and Stacey, G. 1989. Homology in endosymbiotic systems: The "symbiosome". Pages 220-225 in: Molecular Genetics of Plant-Microbe Interactions. R. Palacios and D. P. S. Verma, eds. American Phytopathological Society, St. Paul, MN.

Sandal, N. N., Bojsen, K., and Marcker, K. A. 1987. A small family of nodule specific genes from soybean. Nucleic Acids Res. 15:15071519.

Sandal, N. N., and Marcker, K. H. 1988. Soybean nodulin 26 is homologous to the major intrinsic protein of the bovine lens fibre membrane. Nucleic Acids Res. 16:9347.

Santoni, V., Rouquie, D., Doumas, P., Mansion, M., Boutry, M., Degand, H., Dupree, P., Packman, L., Sherrier, J., Prime, T., Bauw, G., Posada, E., Rouze, P., Dehais, P., Sahnoun, I., Barlier, I., and Rossignol, M. 1998. Use of a proteome strategy for tagging proteins present at the plasma membrane. Plant J. 16:633-641.

Simonsen, A. C. W., and Rosendahl, L. 1999. Origin of de novo synthesized proteins in the different compartments of pea-Rhizobium sp. symbiosomes. Mol. Plant-Microbe Interact. 12:319-327.

Soll, J., and Tien, R. 1998. Protein translocation into and across the chloroplast envelope membranes. Plant Mol. Biol. 38:191-207.

Streeter, J. G., and Morre, D. J. 1990. Release of bacteroid proteins during the preparation of peribacteroid membrane and peribacteroid space fractions from soybean nodules. Symbiosis 8:161-173.

Takahashi, N., Takahashi, Y., and Putnam, F. W. 1985. Complete amino acid sequence of human hemopexin, the heme-binding protein of serum. Proc. Natl. Acad. Sci. USA 82:73-77.

Terada, K., Manchikalapudi, P., Noiva, R., Jauregui, H. O., Stockert, R. J., and Schilsky, M. L. 1995. Secretion, surface localisation, turnover, and steady-state expression of protein disulfide isomerase in rat hepatocytes. J. Biol. Chem. 270:20410-20416. 
Tyerman, S. D., Whitehead, L. F., and Day, D. A. 1995. A channel-like transporter for $\mathrm{NH}^{4+}$ on the symbiotic interface of $\mathrm{N}_{2}$-fixing plants. Nature 378:629-632.

Udvardi, M. K., and Day, D. A. 1989. Electrogenic ATPase activity on the peribacteroid membrane of soybean (Glycine max. L. ) root nodules. Plant Physiol. 90:982-987.

Udvardi, M. K., and Day, D. A. 1997. Metabolite transport across symbiotic membranes of legume nodules. Annu. Rev. Plant Physiol. Plant Mol. Biol. 48:493-523.

Udvardi, M. K., Lister, D. L., and Day, D. A. 1991. ATPase activity and anion transport across the peribacteroid membrane of isolated soybean symbiosomes. Arch. Microbiol. 156:362-366.

Udvardi, M. K., Price, G. D., Gresshoff, P. M., and Day, D. A. 1988. A dicarboxylate transporter on the peribacteroid membrane of soybean nodules. FEBS Lett. 231:36-40.

Vierstra, R. D. 1996. Proteolysis in plants: Mechanisms and functions. Plant Mol. Biol. 32:275-302.

Weaver, C. D., Crombie, B., Stacey, G., and Roberts, D. M. 1991. Calcium-dependent phosphorylation of symbiosome membrane proteins from nitrogen-fixing soybean nodules. Plant Physiol. 95:222-227.

Weaver, C. D., and Roberts, D. M. 1992. Determination of the site of phosphorylation of nodulin 26 by the calcium-dependent protein kinase from soybean nodules. Biochemistry. 31:8954-8959.

Weaver, C. D., Shomer, N. H., Louis, C. F., and Roberts, D. M. 1994 Nodulin 26, a nodule-specific symbiosome membrane protein from soybean, is an ion channel. J. Biol. Chem. 269:17858-17862.

Weig, A., Deswarte, C., and Chrispeels, M. J. 1997. The major intrinsic protein family of Arabidopsis has 23 members that form three distinct groups with functional aquaporins in each group. Plant Physiol. 114:1347-1357.

Wellner, D., Paneerselvam, C., and Horecker, B. L. 1990. Sequencing of peptides and proteins with blocked N-terminal amino acids: N-acetyl serine or N-acetyl threonine. Proc. Natl. Acad. Sci. USA 87:19471949.

Whitehead, L. F., and Day, D. A. 1997. The peribacteroid membrane. Physiol. Plant. 100:30-44.

Williams, K. L., Gooley, A. A., and Packer, N. H. 1996. Molecular biology-developments in protein science combined with ready access to DNA sequence databases have opened up a new field of biology proteome studies. Todays Life Sci. 8:16.

Winzer, T., Bairl, A., Linder, M., Linder, D., Werner, D., and Müller, P. 1999. A novel 53-kDa nodulin of the symbiosome membrane of soybean nodules, controlled by Bradyrhizobium japonicum. Mol. PlantMicrobe Interact. 12:218-226. 